interval of nearly three hours between taking the acid and the commencement of treatment a fatal termination must have taken place except for the fact that she took the poison on a full stomach, which prevented its quick absorption into the circulation. The urine removed had a slightly dark colour, but no odour of carbolic acid. A sample of the stomach contents was preserved and tested with $\mathrm{HNO}_{3}$ and liquor potassæ, when it turned blood-red, then brown-red, and finally pea-green. The fæces passed had the odour of phenol and were dark olive.green in colour. From a medicolegal point of view the most interesting point about the case is the possibility of swallowing a fairly large dose of carbolic acid without any of it coming in contact with the buccal mucous membrane. In all other respects the symptoms were of a classical type.

'Rirkby-in-Ashfield.

\section{THE FATAL RECORD OF CARBOLIC ACID.}

BY ALFRED EDWIN HARRIS, L.R.C.P., L.R.C.S. EDIN., [MRDICAL OFFICEREOT HEALTH, ST, MARY, IRLINGTON.

ToR a considerable time past chemists, druggists, medical men, and coroners, tugether with the pharmaceutical and medical papers, have been calling aloud on the "powers that be" to place restrictions on the sale of carbolic acid by the simple expedient of scheduling it as a poison. Hitherto their efforts have been in vain, and consequently accidental poisonings and self-murders continue from day to day, when, by classifying it among such drugs as prussic acid, strychnine, arsenic, and even the "vermin killers," it would at once cease to be a means of depriving so many people of their lives, and that, too, in a most painful and cruel manner. From the conversations I have had with many persons who believe that something should be done to prevent its promiscuous sale or distribution, I have proved that they have only a small idea of the extent of the mischief it has effected in recent years. I propose to give a plain statement of the deaths it has caused since it made its first appearance in the records of the Registrar-General in 1864, when a female was accidentally poisoned by it. This death was followed in the very next year by that of a male through misadventure. During the succeeding five years (1866-70) carbolic acid poisonings, accidental or suicidal, increased to 25 , and in each of these years, with the exception of 1867 , some 6 persons met their deaths. These deaths were $1,0,7$, $\hat{0}$, and 11 respectively in the years 1866-70 (inclusive), and of these 2 were the suicides of men in 1869, while in 1870 5 were suicides (two men and three women). These were the first cases of suicide noted in the Registrar-General's reports, and were, unfortunately, only the beginning of that long series which has continued from that day to this. In these five years these suicidal deaths were only 1.0 per cent. of all suicides by poison.

Now there is something very noteworthy about these snicidal deaths-namely, that they occurred immediately after dificulties were put in the way of the public procuring those drugs, which had previously been used for suicidal purposes, by the passing of the Pharmacy Act of 1878 and their subsequent scheduling. From this time forth those persons (particularly women) who sought to take their own lives had recourse in tren greater numbers to that poison (carbolic acid), which they could buy without let or hindrance from any oilman, bucksterer, or druggist. I have intentionally used the words "particularly women," for it is a most remarkable fact that more females than males have deliberately killed themselves with this acid, possibly because they find it readily at hand in their homes where they have been using it as a disinfectant. This is true of each quinquennial period from 1871-75 down to that which only closed with the end of 1895. In the five years 1871-75 there were 128 deaths from misadventure and suicide, or nearly 25 deaths per annum. Of these deaths 42 were suicidal, and of these suicides 23 were women and 19 males. The 42 suicides represented 58 per cent. of the total suicides by poisoning. Now it was in this quinquennial period that an active impulse Fas given to sanitation by the passing of the Public Health Acts of 1872 and 1875 (particularly by the latter), and it is a remarkable circumstance that the suicidal deaths from carbolic acid increased 135 per cent. during the succeeding quinquennial period (1876-80). Surely this looks like "cause and effect," for it was then that for the first time very active sanitary measures were adopted by local authorities, who recommended that disinfectants, carbolic acid chiefly, should be used to abate nuisances and promote health. It was then that this poison came into the homes of the people under the cloak of a welcome guest, only to be discovered later as a traitorous friend. The succeeding five years, 1876-80, showed a still further increase, for the deaths from negligence, misadventure, anã suicide numbered 181 , or a yearly average of 36 . In this period there were 81 suicides, 28 males and 53 females, and these formed 7.8 per cent. of all suicides by every other poison.

In the quinquennial period of 1881-85 the 181 deaths from negligence, misadrenture, and suicide of the preceding five years jumped up to 302 (an annual average of slightly over 60), and of these 191 were suicides. These suicides were an increase of 135 per cent. on the return for the preceding five years, and were 15.6 per cent. of all suicidal poisonings. Of the 191 suicides 92 were men and 99 women. The arerage number of suicicles per annum was 38 from $188 \mathrm{~L}$ to 1885 inclusive. The succeeding five years, 1886-90, showed matters in a no better light, for the total number of deaths rose to 342 , while suicides increased to 215 , or an average of 43 annually, and they were 15.4 per cent. of all suicides by poison. I am unable to give the next quinquennial period in full, because the Registrar-General's returns for 1895 have not been issued, but the returns for four years that I have tabulated show matters in their very gloomiest light. In these four years, 1890-94, 549 deaths occurred through taking carbolic acid either by misadventure or with suicidal intent, and of this number 420 , or 76 per cent., were suicides. In each of these four years on an average 137 persons died from the effects of this poison, and of these 105 died by their own deliberate act. The records of these last four years (1891-4) are most startling, for they indicate that carbolic acid, which was the cause of only 5.8 per cent. of the suicidal poisonings in the 1871-5 period, now occasioned 28.0 per cent. In no one year, with the exception of 1888, did men and women take their lives to a greater number than 64 , but in the last return (1894) 167 miserably ended their existence with it; while in 1891, 63 persons destroyed themselves ; in 1892, 73; and in 1893, 117.

At the present moment suicides with carbolic acid promise to outstrip the united poisonings by oxalic acid, opium, laudanum, prussic acid, cyanide of potassium and strych nine. These in the quadrennial period of 1891-4 were used as a means of suicide in 580 instances, whereas carbolic acid was used in 420 . The time was when laudanum, morphia and opium were the favourite poisons, but now carbolic acid has taken their place, and according to the last available return (1894) the latter caused more than twice as many suicidal deaths as the three former combined, for, whereas the opiates poisoned 82 persons, carbolic acid poisoned 167.

\begin{tabular}{|c|c|c|c|c|c|c|}
\hline \multirow[b]{2}{*}{ Period. } & \multicolumn{2}{|c|}{$\begin{array}{l}\text { All deaths from } \\
\text { carbolic acid } \\
\text { poisoning. }\end{array}$} & \multicolumn{4}{|c|}{ Suicidal deaths. } \\
\hline & 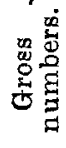 & 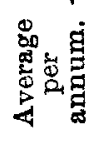 & 苞 & 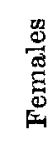 & 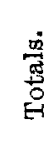 & 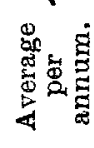 \\
\hline $186 I-65 \ldots$ & 2 & 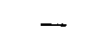 & - & - & 一 & - \\
\hline $1866-70 \ldots$ & 25 & 5 & 4 & 3 & 7 & 1 \\
\hline $1871-75 \ldots$ & 18 & 25 & 19 & 23 & 42 & 8 \\
\hline $1876-80 \ldots$ & 181 & 36 & 28 & 53 & 81 & 16 \\
\hline $1881-85 \ldots$ & 302 & 60 & 92 & 99 & 191 & 38 \\
\hline $1886-90 \ldots$ & 342 & 68 & 97 & 118 & 215 & 43 \\
\hline $\begin{array}{c}1891-94 \ldots . . . \\
\text { (4 y ears.) }\end{array}$ & 549 & 137 & 193 & 227 & 420 & 105 \\
\hline
\end{tabular}

In the period 1861-5 the suicides by carbolic acid were 0.00 per cent. of all suicides with poisons; in 1866-70 they were 100 per cent.; in 1871-75, 582 per cent.; in 1876-80, 7.93 per cent.; in 1881-85, 1537 per cent.; in 1886-90, 1549 per cent.; and in 1890-94 (4 years), 2801 per cent.

This is the fatal record of carbolic acid during the last 35 years. As a set off against its ill deeds it is said to have saved lives as a disinfectant. No doubt it has been very 
useful, but I doubt if it would ever have got a hold on the public but for two facts, one that it was practically the first disinfectant in the field, and the other that it was cheap. Since those early days many disinfectants, some of an absolutely non-poisonous character, have been introduced, and therefore its services are not so requisite as in the past, and it is to these non-poisonous disinfectants that those who have the charge of the health of the people in their hands should turn. It seems to me most absurd that medical officers of health of all men should continue to place this acid so freely in the hands of the public now that its record is known. I have for many years avoided its use when I could, its danger having been brought forcibly under my notice about 1884 through a suicide that occurred in the borough I then presided over. The deaths it has caused we know, the lives it has saved are doubtless not a few; but we also know that other and non-poisonous disinfectants can do their work, and therefore it seems to me that carbolic acid should be put aside from general use and only employed by skilled hands or under professional direction.

Upper-street, $\mathbf{N}$.

\section{ON VARIOUS FORMS OF TALIPES $A \mathrm{~S}$ DEPICTED BY X RAYS. ${ }^{1}$}

BY RICHAR D B A R WELL, F.R.C.S. ENG., CONSULTING SURGEON TO CHARING-CROSS HOSPITAL.

(Continued from page 456.)

VABUS, whether congenital or acquired, is rarely seen as a pure unmixed deformity, but is usually combined with a cert sin and sometimes a considerable amount of equinus, constituting the condition known as equino-varus. Its congenital form is thought by many, ${ }^{2}$ relying on an inward inclination of the neck of the astragalus, to indicate a remotely derived atavism - a recurrence to ancestral prehuman type. It is true that such deflection causes the bone to approach in shape that of anthropoid apes, but deviations of that bone occur in all tolerably severe talipes of whatever class ; if it take place in one direction the bone approaches the simian, if in another the plantigrade, if in a third the digitigrade type. Moreover, such deflections are found in feet which, born perfect, have only during viable life assumed deformity, influenced by some easily traced causation quite independent of developmental errors. ${ }^{3}$ Thus such basis as alteration in the form of the astragalus-neck appears to afford a somewhat narrow foundation for so wide a superstructure, save, perbaps, in some instances of talipedic origin at a very early period of intra-uterine life. For congenital varus may arise either very early-viz., some time between the fourth and tenth week of gestation, when the future skeleton is being sketched out in cartilage or laterthat is, after the third month, when that plan has been for some time complete. To the former period belong certain other malformations, with which club-foot is, however, combined, such as absence of bones or epiphyses, crural, tarsal, or metatarsal, also absence of parts of the central nervous system; likewise those singular truncations with which intra-uterine amputations must not be confounded. ${ }^{*}$ In the latter category of congenital talipes the causal factors are position in utero, the foot abutting either against the walls of that cavity or against some part of the foetal body, or imprisonment of the extremity by amniotic bands or by a loop of the funis. Often the mothers of talipedic infants have told me that during a considerable part of the later months foetal movements have been tumultuous, suggesting the idea of eclampsia, throwing the foot into an abnormal position not afterwards corrected. These conditions of the later congenital varus connote a position of the extremity within the

1 The skiagrams are taken by Mr. Sydney Rowland, late Shuter Scholar, St. Bartholomew's Hospital. 2 Parker and Shattock, Bessel Hagen, Walsham, \&c.

- In my first paper was a sklagram of equinus in which the neck of the astragalus was bent strongly downward (dirritigrade type), yet the deformity originated in paralysis occurring during the fourth year of life.

4. In a goodly number of these cases one may see just emerging from the rounded stump-end tips of minute tingers or toes even with the nails marked out, and these diminutive extremities are usually capable of a certain amount of voluntary llexion, supination, dic. uterus which, cansing divergence in false directions, produces faulty growth and form of bone, and at the same time as the distance between origin and insertion of muscle, fascix, and ligaments is on the one side increased, and on the other diminished, so are these structures developed abnormally long on one side and short on the other. These different constituents (osseous and fibrous) of the deformity are, therefore, neither of them primary nor secondary, but simultaneous ; they both own the same origin, but do not stand to each other in the relationship of cause and effect. Nevertheless, those fibrous structures, short and unopposed or feebly antagonised, maintain the faulty position of the bones and by tying them into false postures influence both before and after birth their further growth, thus adding continually to the false development and malposture.

Acquired varus is caused by paralysis more or less persistent or transient, or to exaggerated clonus with shortening of certain muscles, or even to a posture too long main. tained, ${ }^{5}$ also to contracture, cicatricial or otherwise, of tendons, fascix, or skin. In fact, barring external surroundings, acquired has much the same causation as the later forms of congenital varus. The weakened or lengthened muscles are in this form of talipes the abdac. tors and external rotators-viz, the peronei-and unti a high grade of deformity be obtained the extensor longus digitorum; secondarily, and of less importance, the muscles on the outer side of the sole. The

FrG. 8.

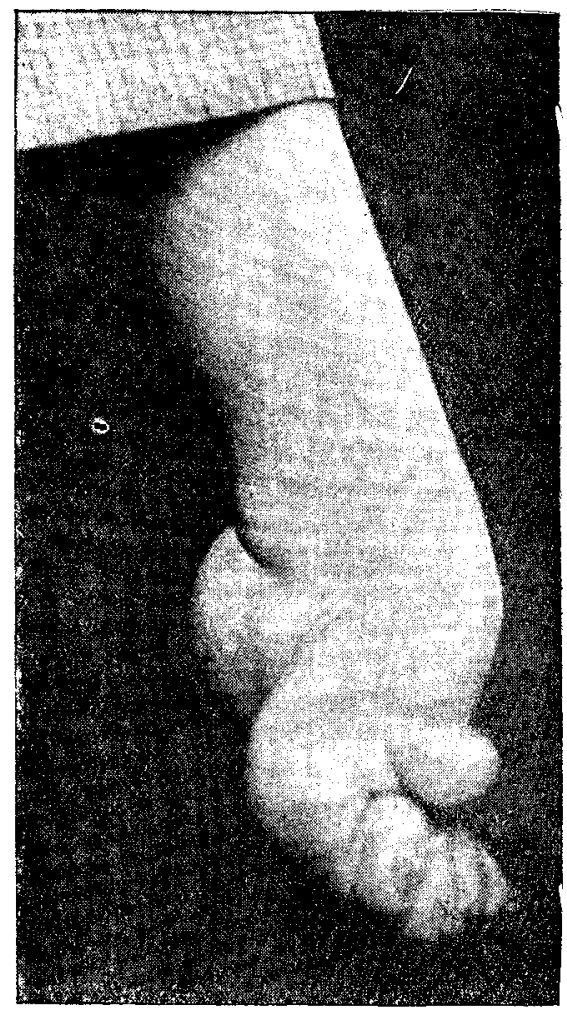

Talipes equino varus (girl aged sixteen years).

contractured ones are the anterior and posterior tibials and unless, which is unusual, some calcaneus be present the surals, nearly always the extensor longus hallucis, is involved, and in severe cases the flexor also. After a certain period of malposture the muscles, ligaments, and fascix on the inner margin of the foot adapt themselves by contracture to this new position. The last two change much in form. I have seen the inner border of the plantar fascia thickened and, as it were, rolled up almost into the shape of a round cord; ligaments become matted togethe and shift somewhat their places of attachment. Thus the anterior border of the deltoid gets mixed with the inner margin of the anterior ligament of the ankle-joint, and both with the superior astragalo-scaphoid, forming a band interspersed with cord-like thickenings, which, however, has been described by Mr. Parker and Mr. Shattock as a capsule. Also the inferior calcaneo-scaphoid ligament is in severe cases very much shortened. All these forces-riz, the excessive or unopposed contraction of the tro

5 More than one case of varus has been published-produced by a painful ulcer or corn on the inside of the sole. I have successfully treated a well-mark $d$ equinus due to such an ulcer on the heel, ance have traced up severe cases to long lying in bed with the feet plantar Hexed, as also to children being allowed to sit for lengthened period
without a rail for the feet, which therefore hung pointed down. 